\title{
Compreensão da violência escolar para os atores sociais de uma instituição de ensino
}

\section{The understanding of school violence by the social actors of an educational institution}

Verônica Borges Kappel ${ }^{1}$, Daniela Tavares Gontijo ${ }^{2}$, Marcelo Medeiros ${ }^{3}$, Luciane Soares de Lima ${ }^{4}$

\footnotetext{
${ }^{1}$ Terapeuta Ocupacional, Mestre em Atenção à Saúde. Discente do Programa de Pós-Graduação em Atenção à Saúde, nível Doutorado, da Universidade Federal do Triângulo Mineiro (UFTM). Uberaba, MG, Brasil. E-mail: tokappel@gmail.com.

${ }^{2}$ Terapeuta Ocupacional, Doutora em Ciências da Saúde. Professora Adjunta do Centro de Ciências da Saúde da Universidade Federal de Pernambuco (UFPE). Recife, PE, Brasil. E-mail: danielatgontijo@gmail.com.

${ }^{3}$ Enfermeiro, Doutor em Enfermagem. Professor Titular da Faculdade de Enfermagem da Universidade Federal de Goiás. Goiânia, GO, Brasil. E-mail: marcelo@ufg.br.

${ }^{4}$ Enfermeira, Doutorado em Ciências da Saúde. Professora Titular do Centro de Ciências da Saúde da UFPE. Recife, PE, Brasil. E-mail: luciane.lima@globo.com.
}

\section{RESUMO}

Objetivou-se compreender a violência escolar na perspectiva dos diferentes atores de uma instituição de ensino, no que se refere às manifestações, causas e consequências. Pesquisa qualitativa cujos dados foram obtidos por entrevistas com 27 atores de uma escola pública e submetidos à análise de conteúdo temática. Das falas emergiram as categorias Manifestações da Violência Escolar e Causas e Consequências da Violência Escolar. Os participantes destacaram fatos nos quais se configuravam como vítimas e apontaram manifestações da violência "na", "da" e "à" escola. Relacionaram a gênese da violência aos aspectos relacionais/sociais e, as consequências aos agressores, às vítimas e à própria escola. A compreensão da violência escolar a partir da perspectiva dos diferentes atores possibilitou compreender a complexidade do fenômeno e a importância do desenvolvimento de ações não apenas de profissionais da área da Educação, mas sim de equipes multiprofissionais e intersetoriais visando a prevenção e enfrentamento da violência escolar.

Descritores: Violência; Saúde Escolar; Criança; Adolescente; Saúde Pública.

\section{ABSTRACT}

This study set out to understand school violence from the perspective of different agents of an educational institution, using qualitative research with data obtained through interviews with 27 actors in a public school and submitted to thematic content analysis. The categories Manifestations of School Violence and School Violence Causes and Consequences emerged from the conversation. Participants highlighted situations in which they portrayed themselves as victims, pointed out manifestations of violence "in," "from," and "towards" school. They related the genesis of violence to relational/social aspects, and the consequences to offenders, victims, and the school itself. The understanding of school violence from the perspective of different stakeholders enabled us to understand the complexity of the phenomenon and the importance of developing actions not only from education professionals, but from multidisciplinary and intrasectoral teams aiming to prevent and work against school violence.

Descriptors: Violence; School Health; Child; Adolescent; Public Health. 


\section{INTRODUÇÃO}

A violência é um fenômeno complexo caracterizado por ações intencionais de indivíduos, grupos, classes, nações, que podem ocasionar danos físicos, emocionais, morais e/ou espirituais a outrem ${ }^{(1)}$. Especificamente em relação às crianças e adolescentes, a violência se configura como um desafio à saúde pública, presente em vários espaços sociais, inclusive na escola ${ }^{(2)}$.

A questão da violência, incluindo a violência escolar, pode ser compreendida a partir de diferentes perspectivas $^{(1-3)}$. Neste estudo considera-se a violência de acordo com os pressupostos da Organização Mundial de Saúde (OMS) apresentados no Relatório Mundial sobre Violência e Saúde. Neste relatório a violência é compreendida numa perspectiva ecológica, que considera a inter-relação dos níveis individual, relacional, comunitário e social $^{(1)}$.

Além dessa perspectiva ecológica, especificamente em relação à violência escolar é importante a realização de distinções conceituais sobre a violência "na" escola, a violência "à" escola e a violência "da" escola ${ }^{(4)}$. A violência "na" escola ocorre dentro do espaço escolar sem ligação à natureza e às atividades da instituição. A violência "à" escola está ligada à natureza e às atividades da instituição escolar, isto é, alunos praticam violência diretamente à instituição e/ou aqueles que a representam. A violência "da" escola é uma violência institucional e simbólica sofrida pelos alunos devido à maneira que são tratados na instituição ou por seus representantes ${ }^{(4-5)}$.

Independentemente se a violência se caracteriza como "na", "da" ou "à" escola, a sua presença neste cenário tem impacto nas relações da comunidade escolar que se tornam conflituosas, prejudicando o processo ensino-aprendizagem, o desenvolvimento das aulas e o projeto pedagógico. Além disso, destacam-se as consequências da violência escolar para a saúde e bem estar dos sujeitos envolvidos, especialmente no que se refere aos aspectos psicológicos, sociais e físicos ${ }^{(2,5-6)}$.

Os resultados de um inquérito nacional realizado na Tanzânia (África) sobre violência contra crianças apontaram que grande parte dos jovens sofreu violência física pelos professores antes dos 18 anos. Com relação à violência sexual, no trajeto casa-escola, $25 \%$ das garotas e $16,7 \%$ dos garotos já haviam sido vitimizados. Além disso, $15 \%$ das garotas e $12,5 \%$ dos garotos já haviam sofrido este tipo de violência na escola ou em suas dependências $^{(7)}$.

Pesquisa realizada sobre a saúde do escolar em 26 capitais brasileiras e no Distrito Federal com alunos do nono ano do ensino fundamental trouxe que a proporção de escolares que deixaram de ir à escola nos 30 dias anteriores à pesquisa por não se sentirem seguros no caminho casa - escola foi de 6,4\%. Além disso, 9,7\% alunos de escolas públicas e 5,5\% de escolas privadas faltaram às aulas devido à sensação de insegurança ${ }^{(8)}$.

No entanto, o fenômeno da violência escolar, assim como outras formas de violência envolvendo adolescentes, não se restringe aos grandes centros urbanos, sendo também encontrado em cidades de menor porte no interior do país ${ }^{(2,9)}$. Estudo realizado no município cenário desta pesquisa em 27 escolas públicas municipais, com participação de 1.042 alunos do nono ano do ensino fundamental evidenciou-se que 604 alunos (58\%) percebem a presença de violência na escola; 804 alunos $(77,1 \%)$ já presenciaram, pelo menos uma vez, brigas dentro de sala de aula; 814 (78,1\%) referiram conhecer colegas que já foram humilhados por outros colegas pelo menos uma vez; 687 estudantes (66\%) disseram que já viram, ao menos uma vez, alunos destruírem patrimônios da escola ${ }^{(2)}$.

A presença da violência no contexto escolar suscita o planejamento e sistematização de ações de prevenção e enfrentamento de cunho intersetorial que sejam subsidiadas também pela compreensão de como o fenômeno se manifesta, o que o causa e como este impacto no cotidiano institucional em diferentes contextos sociais.

Especificamente no que se refere ao campo da saúde, análise da literatura brasileira sobre o tema aponta que a maioria dos estudos se direcionam para grandes centros 
urbanos em detrimento de cidades de médio e pequeno porte ${ }^{(2,10-11)}$. Além disso, observa-se que de uma forma geral, os estudos já publicados abordam a violência escolar a partir de atores específicos de forma isolada, sendo raramente encontradas pesquisas que realizem, de forma concomitante e articulada, as percepções de gestores, pedagogos, professores, alunos e outros profissionais que atuam no cotidiano escolar ${ }^{(8,10-13)}$.

Considerando estes aspectos, este artigo objetivou compreender a violência escolar, na perspectiva dos diferentes atores de uma instituição de ensino, no que se refere às suas manifestações, causas e consequências.

\section{PERCURSO METODOLÓGICO}

Estudo descritivo de abordagem qualitativa realizada em uma escola pública municipal de uma cidade do interior de Minas Gerais/Brasil, escolhida devido a pesquisas anteriores que apontaram a existência da violência de forma significativa, tanto na instituição como na comunidade em que esta se insere ${ }^{(2,9)}$.

Participaram do estudo gestores (diretor, vicediretor, coordenador pedagógico), professores, auxiliares de serviços gerais, estudantes do nono ano e seus responsáveis legais. Para participar do estudo todos os atores deveriam frequentar o período matutino há no mínimo seis meses. Os alunos deveriam possuir até 18 anos e ter a autorização de seus responsáveis. A definição do número de participantes foi realizada por procedimentos de saturação por exaustão ${ }^{(14)}$.

Os dados foram coletados no período de março a junho de 2012 por entrevistas individuais semiestruturadas realizadas com todos os participantes, exceto os alunos que participaram de uma entrevista coletiva. O roteiro de entrevistas, comum a todos, abordou questões relativas às causas, às consequências e às modalidades da violência escolar.

As entrevistas, realizadas em locais que asseguraram a privacidade dos sujeitos, foram gravadas em meio digital e posteriormente transcritas e submetidas à análise de conteúdo temática numa perspectiva qualitativa $^{(15)}$. O processo de categorização, subsidiado pelos referenciais teóricos anteriormente citados $^{(1-4)}$, resultou nas categorias temáticas "manifestações da violência escolar" e "causas e consequências da violência escolar".

A pesquisa foi aprovada projeto pelo Comitê de Ética em Pesquisa com Seres Humanos da Universidade Federal do Triângulo Mineiro (protocolo no 2094/2011). Para a realização das entrevistas os participantes foram contatados previamente e antes do início o entrevistador apresentou os objetivos do estudo e solicitou a assinatura do Termo de Consentimento Livre e Esclarecido (TCLE). Para assegurar a confidencialidade e o anonimato foi atribuído um código a cada entrevistado com idade superior a 18 anos e um pseudônimo escolhido pelos adolescentes.

\section{RESULTADOS}

Participaram 27 sujeitos, entre eles três gestores, nove professores, três auxiliares de serviços gerais, sete estudantes e cinco responsáveis ou pais de estudantes do 9o ano. Com relação ao tempo de experiência na docência, entre professores, sete (78\%) possuía tempo de trabalho na educação superior há uma década, predominando mulheres. O grupo de auxiliares de serviços gerais foi composto exclusivamente por mulheres, com idade média de 46 anos e tempo de trabalho naquela escola superior a nove anos. $\mathrm{O}$ grupo dos pais foi composto por cinco mães, com idade média de 36 anos. Entre os estudantes participaram quatro meninas e três meninos, que em sua maioria tem tempo de frequência na escola superior a cinco anos e com idade de 14 anos em média.

\section{Manifestações da violência escolar}

Esta categoria está construída com base nos conteúdos referentes às percepções dos sujeitos sobre como a violência se manifesta no cenário escolar, principalmente no que se refere às tipologias dos atos violentos e os sujeitos envolvidos nestas situações. Esses 
conteúdos foram categorizados em violência "à", "da" e "na" escola(4).

As modalidades que tiveram maior ênfase em cada grupo foram àquelas referentes às situações nas quais os próprios atores se configuravam como vítimas da violência escolar. Assim, para os estudantes, as modalidades mais citadas foram a violência "da" e "à" escola; para os auxiliares de serviços gerais foram as modalidades "na" e "à" escola; para os pais foram a violência "à" escola e "da" escola e para os professores as modalidades "na" e "à" escola. Apenas para os gestores, as diferentes modalidades de violência escolar obtiveram uma equivalência em número de citações.

Em todos os grupos, a violência "à" escola foi a modalidade que mais se manifestou principalmente a violência verbal cometida pelos alunos contra os professores:

responder os professores(...) os professor falam e eles dão marretada, não respeitam (mãe 4).

Apenas os auxiliares de serviços gerais e os pais apontaram como violência "à” escola a violência física praticada pelos alunos contra os professores:

mais aluno contra o professor do que professor contra aluno. Já vi mais o aluno agredir o professor com palavras e tacar alguma coisa (mãe 3).

A violência cometida pelos alunos contra objetos pertencentes ao patrimônio público da escola (como ventiladores, carteiras, vidros) também esteve presente no discurso de grande parte dos atores escolares:

brincadeiras lá dentro da sala mesmo, jogar roupa no ventilador que está funcionando, estragar ventilador (aux.2).

Além disso, os professores apontaram como aspectos relativos à violência "à” escola, aquela cometida pelos alunos contra o patrimônio pessoal dos professores: já aconteceu de arranharem o meu carro aqui na porta da escola por problemas(...)o menino também já foi expulso (prof.1).

Os professores pontuaram também a violência (agressões verbais) praticada pelos pais contra os professores dentro da escola (agressões verbais):

Esse negócio da violência agente sofre também dos pais quando são chamados. Tem aqueles pais que acabam ofendendo o professor, que acabam jogando a culpa em cima do professor (prof.3).

A modalidade referente a violência "na" escola foi expressa, na maioria das vezes, a partir de relatos que envolvem episódios entre os alunos e a partir da presença de violência verbal (psicológica) entre estes, conforme apontou o Gestor 3:

as vezes um bate boca ou algo que aconteceu fora da escola e vem fazer a culminância dentro do ambiente escolar. Então, eu considero ela escolar.

Os auxiliares de serviços gerais, os pais e professores apontaram também a existência da violência física entre os alunos:

aqueles lá são terríveis, como se diz, aqueles lá não medem consequência. A gente já teve aluno de brigar de arrancar sangue um no outro (aux.2).

Além das situações de violência entre os alunos, os professores relataram a existência de conflitos, principalmente de cunho psicológico entre os colegas de trabalho:

acaba vez ou outra acontecendo tipo de colega, igual de profissional para profissional pessoa que não ocupa uma posição de liderança quer mandar no outro, falar de qualquer jeito com o outro, tirar a autonomia do outro (prof.3). 
Nesta modalidade também há relatos de professores sobre episódios de violência dos pais contra seus filhos dentro do ambiente escolar:

já escutei assim, na minha frente: "eu não te pari eu te caguei !" Aí eu pensei para que eu chamei essa mãe aqui? Pra que né? Quer dizer você fala da violência e ela trata com violência (prof.2).

Os diferentes grupos, com exceção dos alunos, apontaram também a entrada de armas, bebidas e drogas na escola:

agente teve três casos de bebida na educação física. Trouxeram a bebida dentro da garrafinha de água, como se fosse água (gestor 2).

A violência "da" escola foi caracterizada principalmente a partir de episódios de violência verbal (psicológica) praticada pelos professores contra os alunos:

assim tem uma professora aqui que quase ninguém gosta dela. Ela fala tipo que gritando constrangendo a gente (Vitória- aluna).

Eu faço cara feia mesmo... não adianta tampar o sol com a peneira e dizer que não, não existe e tal. Existe sim. Tem dia que você não tá bem (prof.2).

Os professores e os gestores ressaltaram como violência da escola contra professores e gestores, numa perspectiva mais ampla em relação ao sistema educacional, o não cumprimento de leis e as limitadas propostas salariais:

assim, existe uma Lei que fala que o professor não é obrigado a dar avaliação substitutiva se o aluno não conseguir e no final se o aluno não teve um bom envolvimento (...) então, segundo a Lei eu não sou obrigada a dar a avaliação pra esse aluno. Só que a escola obriga, não só essa escola como todas as outras obrigam a dar avaliação substitutiva. Pra que existe essa Lei? (prof.3).

\section{Causas e consequências da violência escolar}

O conteúdo desta categoria refere-se às causas e consequências da violência escolar, organizados com base no modelo teórico proposto pela $\mathrm{OMS}^{(1)}$.

Em relação às causas da violência escolar, considerando o nível individual, os auxiliares de serviços gerais, os professores e os pais trouxeram que algumas características individuais como a personalidade e a essência do sujeito podem ser identificadas na gênese do fenômeno em estudo.

No nível relacional, todos os grupos apontaram como potenciais causas da violência escolar as formas de estabelecimento das relações sociais entre os adolescentes, os problemas de comunicação e a disputa por poder.

Os pais relataram que o próprio grupo de amizades pode se caracterizar como potencial causador da violência escolar:

essas turminhas é onde gera muita violência. Os meninos influenciam muito um aos outros, a amizade (mãe 4).

A influência do grupo nas situações de violência também é destacada pelos alunos que compreendem muitas destas como brincadeiras típicas da adolescência (como colocar apelidos, xingar, inventar mentiras sobre o colegas, "brincadeiras de mão"):

começa quando os amigos (...) começa a se achar muito e começa a fazer gracinha pro outro e ri. Aí tipo, aconteceu no recreio (...). Um foi lá e deu uma rasteira nele. Aí ele caiu e depois levantou e já queria brigar, mas, o que deu a rasteira queria fazer gracinha pros outros rirem. Aí tem o famoso "pressionista" aquele menino fica lá pressionando pra brigar mais fica lá na roda aplaudindo fica rindo... Aí a briga acontece (aluno Will) 
Outro aspecto relacional compreendido como potencial causador da violência escolar para os participantes (com exceção dos alunos) é o estabelecimento das relações afetivas, entre elas os namoros, as paqueras e as disputas por garotas e garotos:

outras situações que eu falo é de namoro se mexeu com a que tá paquerando do outro (gestor 1).

Apenas os estudantes trouxeram explicitamente a disputa de poder como causadora da violência:

ah, tipo, sei lá. Tipo, quer ver quem é melhor. É tipo quem quer aparecer mais (aluno Teddy).

Quem é mais forte (aluno Will).

Ainda no nível relacional, as dificuldades vivenciadas no contexto familiar, foram citadas por todos os grupos, com exceção dos alunos, como causadoras da violência escolar, sendo que os atores destacaram que a escola pode se configurar como um espaço de reprodução da violência vivenciada em casa:

ele atentava todo mundo, brigava, xingava todo mundo, ficava fazendo piadinha zuava os outros amiguinhos e ele dentro de casa ele sofria. Tinha uma vida sofrida apanhava do pai, da mãe, do padrasto sei lá. Passava necessidade. Eu acho que trás muito de casa pra escola (mãe 1).

A limitada participação familiar na escola e a dificuldade em oferecer limites aos filhos foram apontadas pelos gestores, auxiliares e professores como potenciais causas da violência escolar:

tem criança aqui que vem pra escola e fica o dia todo. Então você vê que essas crianças já são aquelas criança mais agitadas eles não tem muito convívio com a família (aux.3). Eu acho que a questão é uma palavra chave: limites. No dia de hoje que nós estamos vivendo a família não está conseguindo impor limites (gestor 3).
No nível comunitário, um baixo interesse dos professores para com os alunos também foi apontado como causa da violência escolar, sendo este entendido como consequência da limitada remuneração dirigida à este profissional:

eu não sei se é pelo salário que eles ganham (...) eu acho que falta amor ao próximo, está faltando e atitude mesmo do professor prestar mais atenção (mãe 1).

Além das causas apontadas acima, partilhadas pela maioria dos grupos, os gestores e professores salientaram ainda questões relacionadas á mídia que podem ser alocadas no nível social do modelo da $\mathrm{OMS}^{(1)}$. A mídia, através de programas de TV, filmes e músicas é compreendida como um meio perpetuador da violência de forma geral:

a violência hoje é pública. Você vê nos filmes, nas novelas, noticiário. Tudo gera violência. Se você for ver os programas de televisão todos tem sinal de violência e os nossos alunos veem tudo isso. Eles passam 5, 6 horas na frente da televisão (...) então nossos alunos eles veem um desenho animado de luta que pega o amigo e joga no chão, eles fazem isso com os colegas deles adotando a postura do desenho (prof. 2).

Ainda no nível social, professores, gestores e pais apontaram aspectos relacionados ao sistema educacional na gênese da violência escolar. Nesse sentido, destacaram transformações no sistema educacional no que se refere à absorção de grande parte das funções e necessidades sociais:

a escola está pegando uma função que não é dela. Eu consigo pensar numa desestrutura da educação em que tudo vai para dentro da escola: droga, trânsito, dengue. A escola tem um papel estranho, as vezes política, tudo tudo dentro da escola (prof. 9). 
Além das transformações no sistema educacional, os professores, gestores e pais salientaram como causas da violência escolar as condições de trabalho limitadas dos funcionários da escola:

professor fica nervoso porque o salário tá baixo e as vezes ele tá num estresse e ele solta. (...) é o tom de voz da palavra (gestor 1).

Finalmente em relação às "consequências da violência escolar" os dados apontaram consequências para as vitimas, agressores e para a escola.

As consequências da violência escolar para as vítimas se relacionaram principalmente as alterações emocionais e psicológicas, nas quais as vítimas sentem-se constrangidas e ofendidas, com possibilidade de aquisição de traumas e diminuição da autoestima:

Eles chegaram e deram uma rasteira nele e todo mundo viu. Ele vai se sentir ofendido em frente dos amigos dele (aluna Gabriela).

Um gesto as vezes dói mais porque uma palmada passa, fica roxo mais passa. Agora um (...) preconceito, uma violação dos direitos, ele fica ali dentro. Às vezes nem mesmo um psicólogo consegue tirar. O corpo fala muito mais que as palavras (gestor 2).

A maioria dos atores também destacou a possibilidade de que a vítima se torne um potencial agressor em relação ao fenômeno:

sempre as vítimas são os mais quietos. Eu acho que eles vão tolerando até certo ponto. Depois eles também explodem (prof.1).

No que se refere às consequências da violência escolar para os agressores, os grupos partilharam concepções relacionadas ao envolvimento em atos infracionais (roubos, envolvimento com gangues), com drogas e até mesmo a possibilidade de morte: eu acho que se não tentar parar ali vai crescer bandido, como se diz. Ele acha que pode tudo [...] (aux.1).

Mexendo com drogas, más companhias (mãe 1).

Depende da violência pode até gerar a morte (Vitóriaaluna).

Além disso, os pais e os gestores destacaram a interrupção dos estudos, a dificuldade de inserção na sociedade e as situações de exclusão para os agressores:

gera indiretamente a exclusão porque essa criança não tá apta a conviver com os demais aqui. Então a escola tem que as vezes buscar meios de transferência. Acaba ocorrendo, de certa forma, uma exclusão para preservar a maioria que é uma atitude de bom senso (gestor 1).

As consequências para a escola foram citadas pelos professores e pais que apontaram que a violência interfere na dinâmica do processo de ensino e aprendizagem de uma forma geral, afetando não somente os envolvidos diretamente nas situações de conflito:

mas quando tem alguma briga, tem alguma coisa no ar a sala fica diferente a gente parece que tá dando aula pra mesa. Aí chama algum aluno porque brigou aí tira da sala de aula aí atrapalha minha aula (prof. 2)

Os professores ressaltaram como consequência da violência para a escola a desmotivação profissional, associada ao desânimo e descrença por parte dos destes em seu trabalho:

eu acho que prejudica muito, mas eu acho que principalmente para os professores é desânimo de trabalhar, desistir. Não dá vontade de ir para a escola, mas de desistir de trabalhar (...) perde os sonhos de ser $e$ tudo (prof. 5).

Professores e gestores também apontaram o adoecimento profissional, manifestado pela somatização 
de questões emocionais e psicológicas e no estresse, como potencial consequência da convivência com a violência na escola:

porque ela estava tão estressada que qualquer atividade ela queria por o aluno pra fora da sala, então, adoece a pessoa (gestor 1 ).

\section{DISCUSSÃO}

Os resultados encontrados refletem a complexidade do fenômeno em estudo e fornecem subsídios importantes para o planejamento de ações de enfrentamento. Destaca-se a baixa adesão dos alunos e dos pais ao estudo, apesar das diversas estratégias de mobilização adotadas pelos pesquisadores. Este fato pode estar relacionado ao receio dos estudantes em participar da pesquisa devido à possibilidade da existência de uma "cultura do medo", e, também a uma baixa participação dos pais no cotidiano escolar.

A análise das manifestações de violência escolar percebidas pelos sujeitos, compreendidas a partir da caracterização em violência “à”, "da” e na escola, possibilitou a identificação de uma tendência dos atores em identificarem com maior facilidade a violência que está diretamente relacionada a eles. Esta tendência pode ter implicações para o planejamento das ações de enfrentamento, uma vez que a adoção de uma visão mais ampla e profunda do fenômeno é vital para a substituição da cultura da culpa pela cultura da responsabilidade no enfrentamento da violência ${ }^{(16)}$.

Especificamente em relação à violência "à" escola, os relatos dos sujeitos podem refletir nuances de um cenário profissional de vitimização dos educadores que abarca o aumento do número de alunos, à heterogeneidade sociocultural presente nas comunidades escolares, as novas demandas de escolarização geradas pela sociedade pautadas em concepções de ensino e aprendizagem diferenciadas, assim como pela fragilidade das políticas educacionais em enfrentar uma realidade dinâmica caracterizada por uma fragilização do lugar social da escola $^{(6,10)}$.

Por outro lado, a violência "na" escola é a modalidade mais divulgada pelos meios de comunicação e a mais facilmente identificada pelos profissionais da escola, pelos órgãos gestores e pelas instituições policiais. Assim como identificado neste estudo, alguns trabalhos indicam que a maior frequência de violência na escola é a que acontece entre os alunos, nas suas mais variadas formas (xingamentos, brigas com e sem violência física, ameaças, roubo de material, rixas de gangues, entre outras) ${ }^{(6,17)}$.

Os achados relacionados à violência entre os funcionários da escola (especialmente entre os professores) e dos pais contra seus filhos dentro do ambiente escolar, não são abordados pelos estudos que subsidiaram esta pesquisa, sendo que estas manifestações foram alocadas na violência "na" escola devido ao caráter relacional e a possibilidade da violência estar ligada ou não às atividades da instituição escolar. Portanto, fazem-se necessárias mais pesquisas para que se possa compreender se essas manifestações são produzidas devido às questões relacionadas à escola, ou se são violências externas à escola que adentram os muros da comunidade escolar.

A violência "da" escola pode ser compreendida como uma violência simbólica, refletindo a reprodução dissimulada das desigualdades sociais dentro da instituição e se manifestando pela ausência de democratização dos sistemas educacionais das sociedades capitalistas $^{(6)}$. A violência simbólica é utilizada como forma de dominação, inclusive por professores e funcionários. As pesquisas têm evidenciado que a violência psicológica praticada contra os alunos na escola é ainda pouco estudada e que funcionários, de modo geral, não se percebem como praticantes, fato este evidenciado na presente pesquisa, na qual apenas dois professores reconheceram suas ações como violentas. Este comportamento caracteriza-se por depreciar o comportamento do aluno, criticá-lo, atribuindo-lhe uma 
posição de humilhação e de inferioridade perante seus colegas, causando constrangimento ${ }^{(6,10,18)}$.

Sob outro prisma, percebe-se que os educadores também são alvos dessa violência ao necessitarem cumprir prazos, programas, preencher cadernetas e formulários, isto é, atender as exigências vindas de um sistema que exclui o educador de sua elaboração e planejamento. Nesse sentido, é identificado nas comunidades escolares o papel paradoxal do professor: como representante do poder, exercendo o papel de dominador; e, de outro, o papel de dominado, submetendo-se as dominações e aos regulamentos burocraticamente estabelecidos, nos quais questões organizacionais administrativas se sobrepõem a pedagogia $^{(6)}$.

No que diz respeito às causas da violência escolar, categorizadas a partir do modelo teórico da OMS, foi possível identificar causas dispersas nos diferentes níveis $^{(1)}$. Nesta perspectiva, ficou evidente que as causas mais citadas pelos sujeitos foram aquelas referentes aos níveis relacional e social, que apontam uma maior responsabilização dos adolescentes, da família e do sistema educacional pela violência escolar ${ }^{(13,19)}$.

Percebeu-se que aspectos comunitários, como àqueles vinculados à própria escola e aspectos individuais, tais como fatores biológicos como impulsividade, histórico de agressão ou abuso não foram elementos apontados com ênfase pelos sujeitos de pesquisa. Aspectos sociais como a desigualdade social, questões étnico-raciais, de gênero, aspectos políticos e econômicos também foram limitados ${ }^{(18-19)}$.

No que se refere às causas vinculadas ao nível relacional, os sujeitos destacaram a forma de construção das relações sociais na adolescência. Sabe-se que a adolescência é uma etapa fundamental do processo de crescimento e desenvolvimento humano, marcada por modificações físicas e comportamentais influenciadas por fatores socioculturais e familiares. Assim, devem ser considerados aspectos relevantes para a adolescência a vivência da afetividade e da sexualidade, o crescimento emocional e intelectual, as relações interpessoais, dentre outros $^{(20)}$.

As brincadeiras fazem parte das relações interpessoais e objetivam aproximar, integrar e incluir. Entre os estudantes, são essas brincadeiras que tornam o ambiente escolar divertido e descontraído, que estimulam a frequência, a permanência, o desempenho, a aprendizagem e o gostar da escola. No entanto, existe uma linha muito tênue entre brincadeira e violência. A brincadeira é caracterizada pelo equilíbrio e divertimento entre as partes, enquanto que a violência se relaciona ao desequilíbrio, na qual uma parte se diverte e a outra é constrangida, humilhada e intimidada ${ }^{(21)}$.

As influências dos colegas durante a adolescência, destacada pelos pais, como possíveis causas da violência escolar são, em geral, consideradas positivas e importantes para a formação de relacionamentos interpessoais, mas elas também podem ter efeitos negativos. $O$ fato de se ter amigos delinquentes, por exemplo, está associado ao maior cometimento de violência pelos adolescentes ${ }^{(1)}$.

No campo das relações sociais, entre elas as afetivas, a violência pode se configurar como estratégia para obtenção de prestigio e utilizada para a resolução de conflitos e "demarcação de territórios". Além disso, para os meninos a violência pode ser valorizada como integrante da identidade masculina hegemônica ${ }^{(22)}$. No entanto, destaca-se também uma percepção crescente da utilização da violência na mediação das relações sociais pelas meninas, sendo a disputa pela atenção dos pares sexuais uma das motivações para este comportamento $^{(2)}$.

Dos inúmeros fatores que envolvem a violência escolar, é de se pensar que, se por um lado as ações praticadas pelo adolescente, no espaço escolar, ultrapassam o que se considera socialmente aceitável, por outro lado, compreende-se que estas atitudes podem ter suas origens na própria realidade vivenciada pelo indivíduo, como uma resposta em alguns casos, às muitas opressões e violências vividas por ele ${ }^{(18)}$. 
O papel que a escola desempenha tem se modificado, uma vez que esta se transformou em um dos mais importantes agentes do processo de socialização de crianças e adolescentes. Isso se deve, em grande parte, às mudanças que ocorreram na composição das famílias, a entrada maciça das mulheres no mercado de trabalho e as alterações no papel que a religião desempenha na vida das famílias. Essa transformação contribuiu para aumentar o número de horas trabalhadas, e, consequentemente limitar as oportunidades para que os pais exerçam seu papel de modelo para padrões de comportamento, valores, crenças e atitudes frente aos seus filhos ${ }^{(17)}$.

Além disso, a família, nos dias de hoje, ao tentar fugir dos padrões autoritários, possui dificuldades em estabelecer novos padrões e limites na educação dos filhos. Na fase da adolescência, a ausência de clareza, a desorientação e a liberdade desmedida que as família muitas vezes asseguram aos seus filhos, acabam levandoos à perda de referências significativas, o que thes complica o desenvolvimento e o amadurecimento psicológicos ${ }^{(10,19)}$.

No entanto, é importante refletir acerca do processo de culpabilização da família, reduzindo o fenômeno, que a priori seria de ordem pública para a esfera individual. A responsabilização, diferentemente da culpabilização, possibilita a compreensão dos contextos onde ocorrem as relações violentas e, portanto, contribui para o planejamento de estratégias que impliquem a família na garantia dos direitos das crianças e dos adolescentes ${ }^{(18)}$.

O limitado interesse dos professores pelos alunos como possível causa da violência escolar pode se relacionar ao impacto das características do sistema educacional (nível social) para as relações na comunidade escolar. Salienta-se a necessidade de melhorias nas condições de trabalho dos docentes, o desenvolvimento de estratégias para sua valorização, investimentos voltados para transformações na formação educativa e disciplinadora presentes nos currículos, bem como oferecimento de suporte que sustente mudanças de práticas $^{(10,19)}$.

Ainda em relação ao nível social, no que diz respeito a mídia como potencial causa do fenômeno, é sabido que, na contemporaneidade, ela disputa cada vez mais espaço com a família, com a escola e com as demais agências socializadoras na educação das crianças e dos adolescentes. Mostra-se, inclusive, mais eficiente na transmissão de valores, assim como na "formatação" das pessoas, sendo instrumento de entretenimento e também educativo. Assim, a mídia pode ser um instrumento que contribui para que adolescentes reproduzam atos violentos e para que estes sejam percebidos como algo natural e banal no cotidiano ${ }^{(18)}$. Por outro lado, a mídia também pode ser compreendida como potencial aliado no enfrentamento à violência escolar ao se caracterizar como dissipadora de práticas e ações desenvolvidas focadas em uma cultura pela paz.

Conforme apontado anteriormente, embora tenha sido observada uma maior valorização, no discurso dos sujeitos, de causas vinculadas aos níveis relacional e social, considera-se que a complexidade do fenômeno em estudo configura-se justamente na inter-relação destes fatores que se influenciam mutualmente. Esta complexidade também se manifesta na observação de que muitas das causas apontadas são diretamente relacionadas às consequências da violência escolar, especialmente no que diz respeito às condições de trabalho docente (consequências para a escola) e às relações estabelecidas entre os adolescentes (consequências para as vitimas e agressores).

As consequências da violência para as vítimas estão relacionadas à idade e as características individuais dos adolescentes, sendo possível a ocorrência de problemas cognitivos, consumo de álcool e drogas, depressão, ansiedade, atrasos no desenvolvimento, perda de apetite e problemas de sono, sentimentos de culpa e vergonha, comportamentos criminosos e violentos de alto risco, hiperatividade, relacionamentos pessoais inadequados, 
baixa autoestima, baixo desempenho escolar, transtornos psicossomáticos, entre outros ${ }^{(22-23)}$.

Em relação aos agressores, sabe-se que estes podem sofrer como consequências problemas cognitivos, depressão, ansiedade, atrasos no desenvolvimento, sentimentos de culpa e vergonha, comportamentos criminosos e violentos de alto risco, hiperatividade, relacionamentos pessoais inadequados, baixa autoestima, transtornos psicossomáticos, comportamentos suicidas e autodestrutivos, perda de produtividade, baixa qualidade de vida, morte e baixo rendimento escolar. Trata-se, portanto, de um problema social grave que afeta não apenas o âmbito escolar e pessoal $^{(6)}$.

Além das consequências para as vitimas e para os agressores, o impacto da violência escolar no cotidiano da instituição, na saúde e motivação dos professores para o exercício profissional também precisa ser valorizado e contextualizado em relação à sua frequência ${ }^{(24)}$. Neste sentido, faz-se necessário diferenciar as consequências de ocorrências isoladas de violência da sua rotinização, já que as primeiras podem, no máximo, chocar momentaneamente os professores, enquanto a segunda tem consequências danosas, podendo até afetar a saúde mental desses profissionais ${ }^{(25)}$. Nesta pesquisa, acreditase que, para os sujeitos participantes, a violência escolar encontra-se mais relacionada à rotina de trabalho do que em atos isolados o que suscita o desenvolvimento de estratégias de enfrentamento com resolutividade positiva no cotidiano dos atores envolvidos.

Salienta-se que as consequências ressaltadas pelos sujeitos não abrangeram repercussões para a sociedade civil, para o governo local, regional e nacional, e para os diversos setores da sociedade ${ }^{(23)}$. Estes achados suscitam reflexões acerca da compreensão dos sujeitos participantes sobre a real magnitude e profundidade da violência escolar e de suas extensões por setores micro e macroestruturais da sociedade.

\section{CONSIDERAÇÕES FINAIS}

Esta pesquisa apontou dados referentes à caracterização que a violência escolar possui para os atores que convivem com ela em um determinado contexto e que, por conseguinte, lidam com suas manifestações e consequências. Por caracterizar-se como um fenômeno complexo e dinâmico, a violência em si exige atenção e intervenções não apenas de profissionais da educação, mas sim de equipes multiprofissionais e intersetoriais que atuem de maneira coletiva e coesa a fim de prevenir e enfrentar a violência escolar.

Nesse sentido, aponta-se o potencial positivo de intervenções dos profissionais de saúde, principalmente a partir de perspectivas da educação popular em saúde. Estas ações podem contribuir para uma maior apropriação e empoderamento dos diferentes sujeitos do/e em seu cotidiano que poderá resultar na construção de um ambiente promotor da paz e de saúde.

Salienta-se que este estudo apresentou limitações relacionadas ao tempo de imersão no campo e a baixa adesão dos alunos e de seus pais. Embora a pesquisa tenha sido realizada em uma comunidade escolar específica e seus resultados não possam ser generalizados para todas as escolas, os dados oferecem subsídios importantes para a compreensão da violência escolar em diferentes contextos e para a elaboração de estratégias de enfrentamento. Percebeu-se a necessidade de estudos de cunho etnográfico, por meio dos quais será possível a discussão das contradições entre os discursos dos sujeitos e as atitudes no cotidiano escolar e de estudos caracterizados como pesquisa ação, focados na análise sistematizada sobre a efetividade de intervenções voltadas para a prevenção e o enfrentamento ao fenômeno.

\section{AGRADECIMENTOS}

Agradecemos a CAPES pelo apoio parcial para a realização da pesquisa através da concessão de bolsa de mestrado. 


\section{REFERÊNCIAS}

1. Krug EG, Dahlberg LL, Mercy JA, Zwi AB, Lozano R. Relatório mundial sobre violência e saúde. Genebra: Organização Mundial de Saúde; 2002.

2. Gontijo DT, Julião CH, Kappel VB, Alves HC, Farinelli MR. Identificação e caracterização da violência escolar: subsídios para ações de enfrentamento. O Mundo da Saúde. 2013;37(1):16-24. 3. Minayo MCS. Violência e Saúde. 1 st ed. Rio de Janeiro: Fiocruz; 2006.

4. Charlot B. A violência na escola: como os sociólogos franceses abordam essa questão. Sociologias. Porto Alegre. 2002;(4):432-43. 5. Souza JKO. Violência em escolas públicas e a promoção da saúde: relatos e diálogos com alunos e professores. Rev Bras Promoç Saúde. 2012;25(1):71-9.

6. Ristum M. Violência na escola, da escola e contra a escola. In: Assis SG, Constantino P, Avanci JQ. Impactos da violência na escola: um diálogo com professores. Rio de Janeiro: FIOCRUZ; 2010. p. 65-93. 7. Tanzania UNICEF; Centers for Disease Control and Prevention, Muhimbili University of Health and Allied Sciences. Violence Against Children in Tanzania: Findings From a National Survey, 2009. Summary Report on the Prevalence of Sexual, Physical and Emotional Violence, Context of Sexual Violence, and Health and Behavioural Consequences of Violence Experienced in Childhood. Dar es Salaam, Tanzania: UNICEF Tanzania, Division of Violence Prevention, National Center for Injury Prevention and Control, Centers for Disease Control and Prevention, Muhimbili University of Health and Allied Sciences; 2011.

8. Malta DC, Souza ER, Silva MMA, Silva CS, Andreazzi MAR, Crespo C, et al. Vivência de violência entre escolares brasileiros: resultados da Pesquisa Nacional de Saúde do Escolar (PeNSE). Cienc. saude colet. 2010;15(2):3053-63.

9. Maricone MR, Alves HC, Gontijo DT. Levantamento a análise de registros e eventos de defesa social (REDS) envolvendo crianças e adolescentes no município de Uberaba em 2010: subsídios para ações intersetoriais. Rev LEVS/ Unesp-Marília. 2012;1(9):113-128. 10. Netto L, Rodrigues RN, Costa MA, Santos J, Tatagiba GA. Experiências e especificidades da violência escolar na percepção de funcionários de uma escola pública. Rev Enferm UFSM. 2012;2(3):591600.

11. Nesello F, Santana FL, Santos HG, Andrade SM, Mesas AE, González AD. Características da violência escolar no Brasil: revisão sistemática de estudos quantitativos. Rev. Bras. Saúde Matern. Infant.

2014;14(2):119-136.

12. Kappel VB, Gontijo DT, Medeiros M, Monteiro EMLM.

Enfrentamento da violência no ambiente escolar na perspectiva dos diferentes atores. Interface (Botucatu). 2014;18(51):723-35.

13. Costa MC, Silva EB, Jahn AC, Dalmolin IS, Santos M, Silva CM. Representações sociais da violência escolar na expressão de jovens estudantes. Rev. Eletr. Enf. 2012;14(3):514-22.

14. Fontanella BJB, Ricas J, Turato, ER. Amostragem por saturação em pesquisas qualitativas em saúde:contribuições teóricas. Cad. Saúde Pública. 2008;24(1):17-27.

15. Gomes R. Análise e interpretação de dados de pesquisa qualitativa. In: Minayo MCS, Gomes SFD. Pesquisa Social- teoria, método e criatividade. Rio de Janeiro: Vozes; 2008. p. 79-108. 16. Aquino TAA, Luna AEA, Oliveira AL, Costa DB, Marinho FL, Rocha MZLSS, et al. Correlatos valorativos da culpa. Religare. 2010;7(2):13646.

17. Silva JMAP, Salles LMF. A violência na escola: abordagens teóricas e propostas de prevenção. Educar em Revista. 2010;1(especial):217-32. 18. Reininghaus GNV, Castro PJ, Frisancho S. School violence: subjective theories of academic advisory board members from six chilean schools. Interdisciplinaria. 2013;30(2);219-234.

19. Maia LLQGN, Rodrigues RN, Costa MA, Tatagiba GA, Santos J. Violência escolar: uma percepção da causa na visão do profissional não docente. R. Enferm. Cent. O. Min. 2013;3(1):539-546.
20. Medeiros SB, Lima KYN, Moreira PNO, Tourinho FSV, Santos VEP. School teen health: a documentary research . J. res.: fundam. care. online. 2014;6(3):1105-1116.

21. Schultz NCW, Duque DF, Silva CF, Souza CD, Assini LC, Carneiro MGM. A compreensão sistêmica do bullying. Psicologia em Estudo. 2012;17(2):247-54.

22. Krause $M$, Torche $P$, Velásquez $E$, Jaramillo $A$. Social representations of violence among young Chileans involved in violence. 2014;13(2):55-66.

23. Devries KM, Child JC, Allen E, Walakira E, Parkes J, Naker D. School Violence, Mental Health, and Educational Performance in Uganda. Pediatrics. 2014;133(1):129-137.

24. Medeiros AM, Assuncao AA, Barreto SM. Absenteeism due to voice disorders in female teachers: a public health problem. Int Arch Occup Environ Health. 2012;85:853-64.

25. Wilson CM, Douglas KS, Lyon DR. Violence against teachers: prevalence and consequences. J Interpers Violence. 2011; 26:2353-71.

Recebido: 24/03/2014.

Aceito: $17 / 02 / 2015$.

Publicado: 30/06/2015. 